\title{
From Language to Postmodern Language Game Theory
}

\author{
Prof., Dr. Le Huy Bac
}

Hanoi National University of Education, Vietnam; Email: Iehuybac@gmail.com

\section{Dr. Dao Thi Thu Hang}

Hanoi National University of Education, Vietnam; Email: daothuhang17@gmail.com

Doi:10.5901/mjss.2016.v7n6p319

Abstract

This study explores the role of language in the postmodern times. We begin by looking at how the postmodernists think about language. They see language as being very important in society and they study language as metalanguage. They believe that language came into being is the same way that society came into being. Everything is governed by language and the way it works. Postmodernists believe that a language has its own life and attains meaning in the way that it is used in real life. In postmodern times game theory has taken on importance. It helps people understanding each other and how to live better. Ludwig Wittgenstein coined the term "language game". He said that upon this foundation people's actions are determined. Based on Wittgenstein's observations, Jacques Derrida, Jean-François Lyotard and many postmodernists have developed the term. Language game has now penetrated deeply into literary theories and many aspects of life.

Keywords: Postmodernism; language games; games; Wittgenstein; theory of games

\section{Introduction}

Language is a means of communication. It is created by human beings in history. Language can reflect many things from society to nature. In use, it more and more becomes a hedge to prevent people from creating. So human beings must to pass over. Many famous writers such as William Shakespeare, Leo Tolstoi, Ernest Hemingway, Harruki Murakami, etc. try their best to give out a new style of language. We can see those in the whole history of literature. And now, in postmodern times language can be also seen as a object to be conquered in the field of art. The writers use theory of language games to composition their works.

\section{Research Methodology}

In order to achieve this paper, we apply many philosophical and sociological methods such as: unity logic and history, analysis and summarize, collective and comparative, synchronic and diachronic methods.

\section{Content}

\subsection{Postmodern views on language}

Understanding the importance of language in postmodern times, Ludwig Wittgenstein said: "Philosophy is a battle against the bewitchment of our intelligence by means of language" (Wittgenstein, 1986). Language was created by human beings in order to communicate in society. During and before the period of the modernism, philosophers and researchers focused on the internal structures of the language and considered it to be a life dominating factor in life. It is postmodernists who consider language to be the method of thinking and subject of life and of course, they do not exclude its nature of the mean and the object. In Tractatus Logico-Philosophicus (1921), Section 5.62, Ludwig Wittgenstein wrote:

"The world is my world" (Wittgenstein, 2001). That kind of "my world" is tested through language. Without language, no one can claim what is mine and what is not mine. The philosopher advises us: "What we can not speak about we must pass over in silence" (Wittgenstein, 2001). 
Appreciating the role of language, many postmodern philosophers built up their theories on the basis of language. Overall, postmodern philosophy comes from two sources: One is guided by ontology, inherited from Martin Heidegger (1889-1976), and the other is derived from language, often called language phylosophy. However, from the perspective of language and whether it is rooted in ontology or not, it must follow a certain language game and be legalized into life.

A Dictionary of philosophy by A.R. Lacey mentioned Wittgenstein, who initiated the "language games", as follows: "All his works but the first were published posthumously. In the first he tried to preserve an extensionalist logic, which led him to trace the limits of what could be stated explicitly and what could only be shown. The second revolves around his rejection of the view that there can be words which have meaning by standing for inner experiences private to the experiencer; this led him to think that philosophical puzzlement in general grew out of misunderstandings of how language works" (Lacey, 2005, p.381).

This statement is absolutely true about the nature of postmodern philosophy and the extraordinary contributions by Wittgenstein to social sciences, especially his vision of language. Language in the second half of the twentieth century has become the top object of interest by philosophers. Simply, there is the awareness that all existence is through language. Things might exist before language could name them, but the concept of the thing could not be vocally communicated to other people like the Ryoan-ji Zen garden in Ryoan-ji Temple located northwest of of Kyoto, Japan. This garden has 15 rock blocks, but only 14 blocks can be seen when standing at any location in the garden. One block is always hidden from view. So, if we do not see a thing, would we dare to affirm that it exists? Of course, it is impossible to make such a conclusion. There exist too many things that we do not know about in this world. They are there but they are out of our perception until they become known. An activity of man is to name unknown things. All of man's naming is done through the use of language and most of it is accidental and arbitrary. At the time of the naming of a thing, the person (or community) has an opinions about things. When a person enters a foreign culture, he will make mistakes. To avoid acting or speaking in an unacceptable manner, he will learn to behave within the norms of the foreign culture. For example, the word for "ox" is, for the Hindu people of India, associated with the reincarnated spirit of dead people while to Vietnamese people it is associated with an animal that pulls a plow and tastes good. The word "whale" denotes a large marine mammal that lives in the sea. To the Japanese, the whale is a delicious food while to Vietnamese fishermen who are living on the coast, a small percent of the Vietnamese population, the whale is a sacred creature and every time they find a dead whale, they bury it and pray to it believing that the spirit of the dead whale will protect them when they fish out at sea. Sometimes they even build a temple to honor a particularly large dead whale.

Used not only to identify things and phenomena, language is also a tool of thinking. The functional vocabulary of a person indicates his or her capacity for thinking and attaining information. In addition, language is a measure of human perception. In Tractatus Logico-Philosophicus, Section 5.6, Wittgenstein says: "The limits of my language mean the limits of my world" (Wittgenstein, 2001). Awareness is always changing as one gains additional information and awareness of scientific achievements takes place. Meanwhile, man's practice of science never stops developing as our external world, in terms of both the physical and mental aspect, is always a challenge to our cognitive ability. As scientific discoveries are made, words to describe the new things or concepts are created. The boundary between what humans know and don't know is always shifting and is identified by additions to the language.

Postmodern philosophy leans towards spiritual values. This philosophy uses rationality to review and reject rationality in order to further promote the development of rationality. The key to their argument is the capacity, way and performance of language. They study semantic word games and look at aspects of language. Most postmodern philosophers think on this basis.

\subsection{Theory of games}

It was not until postmodernism that scholars took game theory seriously. Since then, game theory has entered educated people's daily lives extensively and intensively. If one looks at the nature of any one area of human life, one would see some type of game. For their efforts in applying game theory to the marketplace, two American economists won the Nobel Prize in 2012. Thanks to game theory, countries all over the world have ceased to hold extreme domestic and foreign political lines and policies. It can be said that game theory is the foundation for all aspects of current existence. Games present a balance and create an impetus for development. In the past, people also existed within one or several games but of this they were not aware. Today, mankind is aware of what kinds of games they are playing. So, we can now say that due to an understanding game theory people can understand the secrets of success and happiness in life.

Game theory seems to be present in most areas of human life. However, it can not be a grand narrative that manages everything. Ken Binmore points out certain limitations. "With such a wide field of application, game theory would be a universal panacea if it could always predict how people will play the many games of which social life largely consists. 
But game theory isn't able to solve all of the world's problems, because it only works when people play games rationally. So it can't predict the behaviour of love-sick teenagers like Romeo or Juliet, or madmen like Hitler or Stalin. However, people don't always behave irrationally, and so it isn't a waste of time to study what happens when people put on their thinking caps. Most of us at least try to spend our money sensibly - and we don't do too badly much of the time or economic theory wouldn't work at all" (Binmore, 2007, p.2).

The "playful" of the "game" is opposed to the "serious" of the "center". In an orderly society, the "playful" is in the scope of the "periphery", the "serious" is at the "center". The "playful" is in petit narrative while the "serious" is under grand narrative. From the viewpoints of dualism, the "serious" tends to eliminate the "playful". Whereas, from the viewpoint of monism, the "playful" always includes the "serious". The "serious" is a kind of "playful" and a part of the game. In terms of narrow meaning and real nature, "game" came to life in order to overthrow or reform the grand narratives, the centers and the orthodox which have become old and barren concerning humorous and serious.

Therefore, most postmodern games decentralize and melt out the "grand narrative". The power of decentralizing game is the overall synergy of the "fragmentations", not of the centers. It is part of the theory of collective power that is included in Marxism. Accordingly, if there exit single individuals with equal positions and contributions regardless of their dependence on each other, power will surpass any other structures of the center. Looking back at the road that lead to the Spanish football team's Euro 2012 championship, we can clearly see an application of decentralized game theory. Coach Vicente del Bosque did not put a striker in his starting lineup. This means there is a lack of a team center upon which midfielders can focus. Therefore, the power of the team was dispersed among six midfielders. This strategy is unprecedented in the history of football. By using this decentralized football philosophy, Vicente del Bosque's team was very difficult to beat and they gained the complete admiration of football fans.

When it comes to games, we usually think of something that is childish, rakish, not serious or economically efficient, and which just to serves the purpose of personal entertainment. But games are the most effective way in reducing stress and increasing excitement and creativity in participants. Therefore, the thinking and creativity of scientists, artists or powerful leaders usually have the style of a certain game.

Literally, "play" means doing something that is without hard effort, outside of the usual rules and standards, and entertainment orientated. Previously, governments never said "we are playing the game of national liberation" or "we are playing the game of women's liberation" when there were talks about national or world matters. This "serious" thinking is a myth or a legend that leads to one side being a major party and the other side a minor party. The major party is always right while the other side (usually people who do not have same behavior or disagree with behavior of the major party) is always wrong. This kind of polarized thinking has lasted for thousands of years and has led to permanent disagreements and disputes. It is likely that a discourse on game theory will occur when mankind's view of "games" has a less negative meaning.

In the early twentieth century, with the World Wars, the Cold War and the territorial disputes, along with extraordinary advances in science and technology, people came to realize that there will no longer be an eternal truth and all human behavior is ultimately just a certain kind of game. When people are living their lives, they are playing one or more roles. Since that time, mankind's view of each other has become less extreme, no matter what the cultural differences are. At any one time, everyone may be right or may be wrong in terms of a certain aspect. Thus, game theory is the crown theory in the postmodern era.

The nature of games is interactivity. Without interaction, it is impossible to form a wide society or community of human civilization. "Play" is to trace out sympathetic or different voices, high or low positions, worthy or unworthy purposes, and useful or useless meanings for individuals and communities, and once they play with each other, they will find a solution to their own problems. Individual or community conflict occurs when interaction in a certain type of game does not occur or when two rivals are playing the two different games.

In ancient times, people probably had concepts and played games in what they felt was a correct and meaningful way. The Greeks, despite their ability to fight, put hatred aside when they competed in games or sports. When a sports festival ended, they would resume the fight. Historians call it Greek martial spirit and hospitality but the Greeks must have been aware that both the act of fighting and the Olympic competition were just two types of games. At any rate, the ancient Greeks always maintained a peaceful and what was to them proper behavior in any circumstance. Western historians always felt that Greece was a civilized and humane nation.

According to A Dictionary of Philosophy by A.R. Lacey, Game Theory is a kind of Decision Theory: "The mathematical theory of how it is rational to act when confronted with alternatives which have various utilities and various probabilities. Where one is playing against rational opponents, not against nature or "blind chance" (e.g. in taking account of the weather), we have game theory or theory of games. But game theory is sometimes treated as a part of decision theory" (Lacey, 2005, p.78). Thus, game theory, from a philosophical viewpoint, includes accuracy and tension between 
two (or more) competitors with similar perception.

Michel Faucault $(1926$ - 1984) in an interview also mentioned game theory and its basic characteristics. He said: "The game is worthwhile insofar as we do not know what will be the end" (Martin, 1998). Hence, we see that some more characteristics of the game are attraction and unpredictability. It is the same with language games. It needs to be determined in relation to the connotation of the concept of the game.

\subsection{Language games}

Due to the concept that people's perspective on life is always fictional and each one is a complicated, diverse and endless game, the world can be seen as a text written with numerous smaller overlapped sub-texts in postmodern philosophy. These texts, in general, are constructed by language. Postmodernists argued that there was nothing outside of language (Jacques Derrida: "there is nothing outside of the text"), outside of "grand narrative" and "petit narrative" (Jean-François Lyotard), or outside of discourse (Michel Foucault). Language is a super symbol used by people to become aware of the internal and objective world. If one accepts that no perception can take place without language, then each arguement of postmodernists, though called by a different name and in a different area, could be seen as language and "language games". According to the postmodernists, language has become "a subject of thinking" and people have been hindered by language, counter to its "intention". It is not true that people give birth to ideas in a language but rather "Language is the mother of thought, not its handmaiden" (Kraus, 2001). And so language gives a birth to thought. Humans are enslaved by the language that they generated themselves. Thus, the greatest release of people in the postmodern era is freedom from language - language which has been stylized, institutionalized, standardized and abused throughout thousands of years. The use of "language games" brings both language and people out of "grand narrative" and out of the weird power centers which are dominate human behavior and thought.

The first person to propose postmodern language games is Ludwig Wittgenstein, the author of Philosophical Investigations, who is thought to have "no predecessor in philosophy" (Wright, 1955). Wittgenstein believes that the primary nature of language is in relation to competition. He said: "to speak is to fight". The secondary nature of the language is thought by some philosophers to be a multi-game which is made up of many language games with different rules. We find that this concept is similar in chess rules. The two players must adhere to the conventions of the pieces. These conventions are the limitations placed upon the possible actions of each piece but there is versatility in the manner in which the pieces as a group can attack and defend. The unpredictable evolution of movements of each piece and all of the pieces as a whole creates the possibility for many variations of action.

Language is "chess playing" in action. In terms of results: a game has only one of three types of result, win, lose or draw, the result depending on the capacity and intention of the players. Saying that, when it comes to games, we need to have the following elements: context, players, skill, rules and results. For a language, due to metaphor and stylization, there is unlimited game variation. Consequently, the game result is also difficult to predict.

Based on the idea of "competitive language" of Ludwig Wittgenstein, Jean-François Lyotard made a generalization: "It is useful to make the following three observations about language games. The first is that their rules do not carry within themselves their own legitimation, but are the object of a contract, explicit or not, between players (which is not to say that the players invent the rules). The second is that if there are no rules, there is no game, that even an infinitesimal modification of one rules alters the nature of the game, that a "move" or utterance that does not satisfy the rules does not belong to the game they define. The third remark is suggested by what has just been said: every utterance should be thought of as a "move" in a game" (Lyotard, 1987, p.10).

Ludwig Wittgenstein himself was aware of the important role of language at the beginning of his philosophical career but he did not then focus on language games. Rather, he paid attention to language as an object of "internal logic" through the concept of picture language: A theory says that all propositions with meaning are the real function of basic clauses. Later, aware of the generality, diversity, flexibility and mobility of language, he proposed the concept of "language games".

In Philosophical Investigations, Wittgenstein repeatedly referred to this concept. He also distinguished between the earlier language games with fixed characteristics of a language and postmodern language games with their open nature and endless ability to combine to create new meanings, but he did not propose a specific definition. This is a unique to postmodernism. Researchers present the possibility of concepts and leave it to readers to evaluate these concepts.

Philosophers understand the characteristics of "play" in language games and, referring to Wittgenstein, Duncan J. Richter outlined the main features: "They are, first, a part of a broader context termed by Wittgenstein a form of life. Secondly, the concept of language-games points at the rule-governed character of language. This does not entail strict and definite systems of rules for each and every language-game, but points to the conventional nature of this sort of 
human activity. Finally, Wittgenstein's choice of "game" is based on the over-all analogy between language and game, assuming that we have a clearer perception of what games are. Still, just as we cannot give a final, essential definition of "game", so we cannot find "what is common to all these activities and what makes them into language or parts of language" (PI 65)" (Richter, 2009).

Duncan J. Richter said that "language games" include three elements: a live form, convention, and an endless ability to make use of playful variables. The theoretical foundation upon which the game is buildt is "family resemblance", Duncan J. Richter said: "It is here that Wittgenstein's rejection of general explanations, and definitions based on sufficient and necessary conditions, is best pronounced. Instead of these symptoms of the philosopher's "craving for generality", he points to "family resemblance" as the more suitable analogy for the means of connecting particular uses of the same word" (Richter, 2009).

Referring to language games in spirit of deconstruction, Jacques Derrida destroyed Ferdinand de Saussure's Logocentrism concept of the signified and the signifier. He said that no signifier could be purely signified while it can be directed to one or more other signified. He wrote: "Not that the word "writing" has ceased to designate the signifier of the signifier, but it appears, strange as it may seem, that "signifier of the signifier" no longer defines accidental doubling and fallen secondarity. "Signifier of the signifier" describes on the contrary the movement of language: in its origin, to be sure, but one can already suspect that an origin whose structure can be expressed as "signifier of the signifier" conceals and erases itself in its own production. There the signified always already functions as a signifier. The secondarity that it seemed possible to ascribe to writing alone affects all signifieds in general, affects them always already, the moment they enter the game. There is not a single signified that escapes, even if recaptured, the play of signifying references that constitute language. The advent of writing is the advent of this play; today such a play is coming into its own, effacing the limit starting from which one had thought to regulate the circulation of signs, drawing along with it all the reassuring signifieds, reducing all the strongholds, all the out-of-bounds shelters that watched over the field of language. This, strictly speaking, amounts to destroying the concept of "sign" and its entire logic" (Derrida, 1997).

It can be said that Jean-François Lyotard and Jacques Derrida are two of many generations following Ludwig Wittgenstein to use the concept of "language games" in a positive and effective way. In The Postmodern Condition, JeanFrançois Lyotard used the concept of "game" and "language games" hundreds of times. Jacques Derrida played the game on the core concepts with his philosophy name: différance. The term can be seen as "the process of postponing meanings and creating a difference".

When referring to language, philosophers or literature-culture researchers in general do not ignore the meanings of the words. Rejecting the way Saussure using to explain the meanings of words, in Section 43, Philosophy Investigation Wittgenstein said: "the meaning of a word is its use in the language" (Wittgenstein, 1986, p.20e). It can also be specified in the next argument that the definition of the language is the use of a language in language games.

\section{Conclusion}

While establishing the concept of "language games", postmodernists have paid attention to characteristics of metalanguage. Here, we extend the concept of metalanguage to mean not only a description of the language but also a model of the following movement of our lives. Thus, politics, ethics, education, economy, culture, etc. are working on the movement of the language in its games. All the "lives" of a spiritual existence in life do not go out of language and language games. All approaches that humans make to reach the truth are recorded and verified through language games. Language is both a dead world and the resurrection of humanity in thinking and awareness of both ourselves and of the outside world.

\section{Acknowledgement}

This research is in the thesis named "Characteristics in modern Japanese prose of the $20^{\text {th }}$ century", under grant number B2015-17-64.

\section{References}

Binmore, K. (2007). Game Theory: A Very Short Introduction, Oxford University Press Inc., New York, 2007.

Derrida, J. (1997). Of Grammatology, Trans. by Spivak, G. C. Baltimore: John Hopkins University Press. http://www.mohamedrabeea. com/books/book1_3997.pdf.

Kraus, K. (2001). Dicta and Contradicta, trans. by Jonathan McVity, Urbana: University of Illinois Press. 
Lacey, A.R. (2005). A Dictionnary of Philosophy. Taylor \& Francis e-Library.

Lyotard, J.F. (1987). The Postmodern Condition: A Report of Knowledge, Trans. by Bennington, G. \& Massumi, B., Manchester: Manchester University Press.

Martin, L.H., \& Gutman, H., \& Hutton, P.H. (eds.). (1998). Truth, Power, Self: An Interview with Michel Foucault (October 25th, 1982). In Technologies of the Self: A Seminar with Michel Foucault. London: Tavistock, 1988, pp.9-15.

Richter, D.J. (2009). Ludwig Wittgenstein, Stanford Encyclopedia of Philosophy, Stanford: Stanford University.

Wittgenstein, L. (2001). Tractatus Logico-Philosophicus, Trans. by D. F. Pears and B. F. McGuinness, New York: Routledge.

Wittgenstein, L. (1986). Philosophical Investigations, Trans. by G.E.M. Anscombe, Oxford: Basil Blackwell Ltd.

Wright, G.H. (1955). Ludwig Wittgenstein, A Biographical Sketch, The Philosophical Review, Vol. 64, No.4, pp. 527-545. 